\title{
Shifting the Gaze: From the Numerate Individual to Their Numerate Environment
}

Jeff Evans, Middlesex University

Keiko Yasukawa, University of Technology Sydney

David Mallows, UCL Institute of Education

Jana Kubascikova, HM Revenue \& Customs

\begin{abstract}
Drawing on the concept of the "literate environment," the authors conceptualise the numerate environment to explore the development of adults' numeracy. Numerate environments provide opportunities, supports, and demands for numeracy practices. Case studies of domestic energy bills in the UK and of the currency conversion process to the euro in the Slovak Republic from 2009 illustrate opportunities, supports, and demands on adults. We use the idea of affordances to understand inter-relations among these three key aspects. We show the importance of considering affordances at different levels of the environment, which we call here individual, mid-level, and societal or national levels. Implications for numeracy policy and learning are explored.
\end{abstract}

Keywords: numerate environment, opportunities, supports, demands, affordances

This paper contributes to the growing interest and research in adult numeracy by proposing and illustrating a framework for describing and analysing the contexts in which adults engage in numeracy. Several trends have contributed to the increasing attention paid to numeracy as a key adult skill, in addition to literacy and digital literacy. One is the experience of adult literacy tutors over the last 40 or more years in discovering needs for quantitative skills among their students (Coben, 1992). Another is the more recent increase in demands on citizens to manage their own economic and social well-being, with the rise of precarious employment, the roll back of the welfare state in times of austerity (Yasukawa \& Evans, 2019), and changes in the way in which "customer service" support is provided by many private firms (Nayak \& Beckett, 2008). In addition, large-scale assessments of adults' skills, such as the Organisation for Economic Cooperation and Development (OECD, 2013) Survey of Adult Skills, identify numeracy as one of the "key informationprocessing competencies' that are relevant to adults in many social contexts and work situations, and necessary for fully integrating and participating in the labour market, education and training, and social and civic life" (p. 5).

In an earlier paper (Evans et al., 2017), we 
introduced the notion of the numerate

environment as a way of beginning to interrogate how contexts can both afford and constrain numeracy practices. We argued that this in turn has implications for how we might conceptualise assessments of, and initiatives to support, numeracy development. We aim in this primarily conceptual paper to further develop our concept of the numerate environment, by articulating a framework for analysis. We suggest that a numerate environment has the three dimensions of opportunities, supports, and demands for adults' numeracy activity, plus barriers that individuals may encounter. We now group all four of these dimensions as affordances (van Lier, 2000). We explore ways of changing the focus of our analysis of policy and practice in adult numeracy from the (more or less) "skilled" individual to the environment in which that individual functions. We see this environment as made up of various social institutions and organisations, characterised by (recurrent) social practices, that can be understood as functioning at three "levels," we explore these levels in a range of short examples and in two case studies. The three levels we consider here are the micro (the individual in small face-to-face groups), the mid-level (groups and institutions in civil society), and the macro (societal) levels.

We argue that developing the concept of the numerate environment allows those concerned with research and policy to frame the variations in levels of numeracy proficiency among the population, at least partly as a societal, and not merely an individual, problem. Thus, we build on the work of researchers such as Reder (2009) who show how people's literacy and numeracy skills development cannot be fully understood in isolation from their engagement in social practices that call upon the use of such literacy and numeracy skills.

\section{Literature Review}

Debates on adult numeracy have been indebted to several traditions, including adult education, adult literacy, and mathematics education. They have been marked by a strong sense of the importance of the context of mathematical / numerate activities engaged in by adults. Over the years, studies of numeracy practices have emerged drawing on a range of different theoretical resources, including situated cognition, cultural-historical activity theory, and ethnomathematics (Yasukawa, Jackson, et al., 2018). Studies of cognition in practice or "practical intelligence" (e.g., Scribner, 1986) have influenced not only studies of mathematical or numeracy practices, but also literacy practices. In studies of adult education and learning, studies of literacy as social practice (Barton \& Hamilton, 1998; Street, 1985) in turn led to studies of numeracy as social practice (Baker, 1998; Street et al., 2005; Yasukawa, Rogers, et al., 2018). In mathematics education, the debate on the context of mathematical thinking has been central for over 30 years (Greeno, 1991; Lave, 1988; Nunes et al., 1993; Saxe, 1994). Socio-cultural theories on learning that have developed from Vygotsky's (1978) work view learning and development as a cultural-historical activity; they thus direct our gaze not only to the individual adult numeracy learners, but also to their environment, and to how the interactions between individuals and the socio-material resources in their environment make learning and development possible for them.

One of the salient features of the social practice studies of numeracy is their use of ethnographic approaches in order to investigate numeracy practices in-situ and to generate thick descriptions of what people do with numeracy (Yasukawa, Jackson, et al., 2018). While it would be impractical to generate the thick descriptions of numeracy practices that ethnographic studies do, large-scale 
international surveys like the Survey of Adult Skills (PIAAC) and longitudinal studies such as the 10year study conducted in Portland, Oregon (Reder, 2009) provide substantial data about adults' use of numeracy skills that may point to in-depth, in-situ studies, such as that undertaken by Grotlüschen et al. (2019) in the study of numeracy practices of vulnerable adults in the city of Hamburg.

From a socio-cultural and socio-material perspective on practice, understanding adults' use of numeracy skills must involve understanding the context in which the social practices unfold. However, Jackson et al. (2018) found that one of the findings from the studies of numeracy practices is that the contexts of practices themselves are fluid and unstable, and this in turn creates demands for new or modified numeracy practices. For example, they cite the study of migrant workers in Mexico (Kalman \& Solares, 2018) who have to establish new relationships and new forms of financial transactions each time they move from one employer to the next. Not only new social relationships, but introduction of new work processes such as lean manufacturing, and new technologies, as well as removal of social safety nets represent changes in the contexts in which people's numeracy skills are used. While many studies of numeracy as social practice have focused on aspects such as the historical, sociocultural and political dimensions of the numeracy practices, less focus has been given to investigating the ways in which the contexts enable or hinder people's development of numeracy practices.

\section{The Literate Environment}

In our earlier formulation, we drew on the concept of a "literate environment" (Easton, 2014) to suggest ways in which the question can be addressed; Easton himself refers to earlier UNESCO conference proceedings (UNESCO UIE, 1997). In these proceedings, a literate environment refers to the extent to which, in any given social environment, there is "something interesting and/or necessary to read, or situations that required reading and writing in any form, as well as material and infrastructure available, such as books, newspapers, paper" (Lind, 2008, pp. 82-83). Thus, the literate environment is associated, not with the "supply side" of literacy, curriculum, pedagogy, teacher development, management of teaching, measurement and assessment, but with the "demand side," with the actual practices that adults need to engage in as part of their social lives and social interactions, and the ways in which these are opportunities that are encouraged and supported, or not.

The concept of the literate environment suggests that the ways in which information is sought and used within the social environment determine the use and need for literacy. It reinforces the idea that literacy is not a goal in itself. As Easton (2014) points out, where literacy is seen as "autonomous" (Street, 1985), it is assumed that supply of literacy will create its own demand, that once acquired, literacy will "...generate its own practices, and ... inevitably have major effects on both psychic and social development" (p. 42). Easton suggests that a focus on demand provides an important perspective on literacy development: "A lack of concern for the whole environment in which literacy is acquired and used can undermine literacy efforts and offer the learner little chance of using literacy for any desired purpose." (Easton, 2014, p.38)

In its recommendations to the European Commission, the European Union (EU) High Level Group on Literacy (2012) prioritised the development of a literate environment, suggesting that adults' skills respond to and are shaped by the "literate environment" in which they act (Grotlüschen et al., 2016). 


\section{The Numerate Environment}

Inspired by the concept of the literate environment, Evans et al. (2017) proposed the idea of the numerate environment in order to examine adults' experiences in using and developing numeracy in their lives. They constructed a characterisation of the numerate environment as including a series of affordances - including opportunities and supports - and demands for adults to engage in numeracy practices. The numerate environment may also throw up barriers to their taking up those opportunities or supports or meeting the demands from their environment. Following van Lier (2000), we use the term affordance in the sense of Gibson (1986) who views affordance as the relationship between the individual and their environment; thus, it would include all four of the dimensions that we have distinguished. Gibson argues affordances refer to the "complementarity of the animal and the environment" (1986, p. 127). While the affordance of the environment does not change as the individual's need changes, what the individual perceives in the environment may change. In other words, the existence of the numerate environment is an objective reality, but the individual perceives, and experiences, the affordances within it subjectively.

\section{Demands}

We must ask what are the demands (Mallows \& Litster, 2016) on adults' numeracy - at work, or in the other settings of everyday life? What numeracy practices are adults required to engage in as part of their lives as citizens, consumers, employees, neighbours and in other social roles that they play?

Workplace numeracy (and literacy) are clearly areas of rapidly changing practices and skills. According to Worthen (2014), there are always two demands on workers in any workplace: one is the workers' need to "earn a living," and the other is the employer's goal of increasing productivity. This means that workers need to be deploying a continually developing set of skills, to keep up. Otherwise, they will not be able to do their jobs, nor will they be able to assess workplace health and safety risks, nor challenge employers' claims about the need for cuts to jobs, etc., on the basis of "financial necessity" (e.g., Yasukawa \& Evans, 2019).

In the domain of consumer numeracy, examples abound of why "the buyer should beware." Adults may be mystified by sellers' claims about the "better deal" to be had from multi-buy offers or by "new" or different pack sizes. Or there may simply be "mistakes" by sellers, that consumers need to be able to spot; one example of the common "bestbuy" dilemma is given in Evans (2000, p.257).

The increasingly complex demand for financial numeracy is not limited to the purchasing of material consumer goods. The crisis in the vocational education and training sector, leaving hundreds of students with the possibility of large debts due to the operation of unscrupulous operators (Tomazin, 2018) is one example of the risky choices consumers are facing when marketisation takes over traditionally public services.

Our concern should not just be with the increasing complexity of the numeracy required to make informed decisions. We can also identify areas of society in which numeracy demands have been reduced through the use of technology, and other business processes. The Survey of Adult Skills suggests that a high proportion of adults with numeracy at or below Level 1 make little use of their numeracy skills at work. This likely indicates that they are working in jobs that demand little in terms of numeracy.

\section{Opportunities}

We give examples here, of opportunities to engage 
in numeracy practices afforded by the numerate environment. Organisations like National Numeracy in the UK offer a range of resources on their websites: https://www.nationalnumeracy.org. $\mathrm{uk} /$ research-and-resources.

In addition, many opportunities to exercise what might be called "political numeracy" arise from the increasing availability of information in the current "data rich" era (Evans et al., 2019). For example, the Open Data Institute (https://theodi. org), an independent, non-profit organisation, based in London aims to promote the availability and the use of many kinds of data, especially state statistics. Many state statistics (National Statistical Office) websites are increasingly userfriendly. Further, for citizens wanting to get to know the world around them - and their place in it, informative databases have been brought together, and are often freely accessible. For example, Hans Rosling et al.'s Gapminder (https:// www.gapminder.org/) focuses on differences on key indicators among countries of the world ${ }^{1}$.

Recent developments in measurement, tracking, storage, and presentation of data on mobile devices have led to what might be seen as opportunities to self-monitor an individual's physical activities and bodily functions, and to compare them to what are presented as norms or averages (Lupton, 2016). This may lead to the seeming possibility of being more independent of advice from skilled (though, in some places, increasingly scarce) medical practitioners (Yasukawa \& Evans, 2019), and perhaps of strengthening one's health literacy or numeracy.

There is an increasing availability of data on a range of activities in civil society which attract great interest and many "spectators," e.g., sports results and sports performance (e.g., Anderson \& Sally, 2013). This data can be used to engage adults in numeracy practices - the creation of "fantasy sports" teams, imaginary teams made up of players from several actual teams (Smith et al., 2006) attests to this. Fans' interest in their sports creates motivation for exploration of relevant statistics and for predictions and creates opportunities for numeracy learning. In countries which have experienced a "lockdown" of normal activities due to the pandemic of early 2020 (the majority), the existence of databases of past sports performances has allowed "simulations" of competitions. Besides providing entertainment, these may also afford an understanding of the potentials and limitations of mathematical simulations and models more generally.

\section{Supports}

The numerate environment also provides supports for adults to engage in numeracy practices. In the realm of civic / political numeracy, for example, there are supports helping to make available data sets accessible to particular groups of adults ${ }^{2}$ : Thus, many of the databases referred to under "opportunities" also have tools such as dynamic interactive graphics interfaces (and guidance as to how to use them) that support posing questions and investigating them; see Rosling et al. (2018).

In many countries, professional statisticians offer volunteer support to laypersons wanting to use data; for example, in the UK, the Royal Statistical Society and in the United States, Statisticians without Borders. In an era sometimes characterised as increasingly subject to fake news, fact-checkers have sprung up which monitor the statistics and logic used in policy debates in many countries: for example, the BBC and Full Fact in UK (Sippitt, 2019).

The mass media also offer some supports. Among broadcasters, BBC Radio presents "More or Less" ( https://www.bbc.co.uk/programmes/b006qshd); see 
also Blastland \& Dilnot (2008). Among newspapers, Ionika Smeets writes a long-standing column in De Volkskrant, in the Netherlands (Smeets, 2018), which began as a blog from two math girls; see also Paulos (1996). Many financial institutions, as well as national and transnational agencies such as the OECD (https://www.oecd.org/financial/education/ resources/) offer support for the development of "financial literacy" / numeracy, especially for younger people still at school.

\section{Barriers}

Adults also face barriers in accessing the affordances of their numerate environment. These barriers may affect their ability to make the most of the opportunities offered, or to gain support in meeting the demands placed on them. Such barriers can be related to the adults' numeracy, but also to their socio-economic position, and their consequent access to material and social resources.

For example, political parties often fail to give the basic numerical (or other) information that any citizen would need, in order to be able to make informed decisions. The December 2019 election in the UK provided a number of illustrations in the parties' manifestos and spokespersons' statements. In workplaces, the power relations in the workplace can hinder or extend workers' mathematical knowledge. In Williams and Wake's (2007) study in an industrial chemistry lab, the workers were responsible for providing data to their manager, but were completely "black-boxed," or excluded from information about the detailed workings of the calculation process, because the managers controlled the models that produced the calculations and the resulting decisions themselves. Further, people have sometimes suspected free-market firms of trying to obscure and confuse customers, by the complication or proliferation of pricing. In 2014 the UK Energy ombudsman responded by requiring energy firms to reduce the proliferation of tariffs (https://www. ofgem.gov.uk/sites/default/files/docs/2014/03/ assessment_document_published_1.pdf).

The Australian Competition and Consumer Commission (ACCC) has warned consumers about several sorts of barriers: "a business predicting the health benefits of a therapeutic device or health product without evidence that such benefits can be attained; a company misrepresenting the possible profits of a workat-home scheme, or other business opportunity" (ACCC, n.d., para. 1).

\section{Nested Environments}

We also consider the importance of adults' existing in multiple environments in which they interact to varying degrees. In our analysis below of two more substantial case studies, we use a taxonomy of levels of the environment - individual / faceto-face, mid-level, and societal - to refer to the nested environments with which the individual interacts ${ }^{3}$. The individual-level environment consists of household / family, and other regular face-toface relationships and personal social networks. The individual is also located in mid-level settings, including perhaps a workplace, a cultural or religious institution, their labour or trade union social institutions with which the individual may interact little or not at all, but which can constrain or enable the individual's actions. Finally, we can consider the societal or national level (including supra-national groupings such as the European Union (EU)) in which the individual is a resident and/ or a citizen; by virtue of "belonging" to this level, the individual is supported or constrained in certain ways (e.g., tax obligations, ability to work, access to social benefits). We can think of an adult's numerate environment from this nested perspective and consider not only what individual adults 
perceive as learning affordances, but also how the interactions and the interconnectedness between the elements of the different levels of the environment enable the adults to perceive the affordances.

\section{Case Study 1: Domestic Energy Bills}

In this section, we draw on data from a study by the National Research and Development Centre for adult literacy and numeracy (NRDC) of domestic energy bills in the UK, in order to explore the literacy and numeracy demands, opportunities, supports, and barriers that they provide for individuals. The study was carried out for OFGEM, UK government regulator for the energy market (Europe Economics, 2011). It suggests that something as apparently straightforward as "reading" a gas or electricity bill places significant demands on adults' numeracy.

In assessing the numeracy skills required to access information in the bills, references were made to the English Adult Numeracy Core Curriculum which lists the types of numerical tasks which individuals working at each level would be expected to perform. ${ }^{4}$ Given the nature of the mathematics required to read such documents a distinction was drawn between understanding the information presented in the bills, the main charges and payment dates, and interrogating that information, comparing tariffs and working out how the charges have been calculated.

\section{Demands}

Understanding the Total Charge in the bill and the date the payment is due allows the bill-payer to meet the demands of the bill, to pay it. In a typical bill, the numeracy needed to extract this basic information is simpler than the numeracy required to check that the Total Charge is correct, or to interrogate the basis for the calculation. For example, in order to check the Total Charge for a gas bill, it is normally necessary to:

- Understand that the total amount was arrived at by multiplying units and $\mathrm{p} / \mathrm{KWH}$ (pence per kilowatt hour), even though there are no multiplication signs and no pound sign is used in the $\mathrm{p} / \mathrm{KWH}$ column

- Multiply a number without decimal points (but with a comma separating thousands and hundreds) by another number that has three decimal points)

- $\quad$ Take $5 \%$ of pre-VAT (value-added tax) total charge to check the VAT calculation.

Of course, there is no need for an individual to understand how their bill has been calculated. As long as the bill is paid, the demand has been met and the service will continue. However, this places the adult in a passive role, without access to the information needed to make informed choices, such as how to reduce their bill by changing their behaviour or switching energy provider. They may have further questions about the reasons why they are being offered different options about tariff plans or choices about the proportion of their energy usage they want to be matched by energy produced by renewable sources. They may also wonder about the actual material difference any of these choices would make to their financial situation, say, and more widely, to the quality of the environment. An active or critical reader of the bill would be able to make more informed decisions based on the data available.

\section{Opportunities}

The inclusion of particular information in the bill, and the consumer's interrogation of it, provides an opportunity for energy customers to make informed choices about the value of their particular plan. For example, the bill may contain information about the energy usage for the same period in the 
previous year, shown as a comparison in the form of a bar graph. It may contain information about the projected usage for the next 12 months, or suggestions about ways of lowering consumption or about different tariff plans. There may also be information about options for switching to a plan that increases the proportion of renewable energy matched with their total energy use.

These may be perceived by the consumer as opportunities to take actions that would reduce their energy costs and/ or be more environmentally responsible. However, this requires them to engage in more demanding numeracy practices. The energy bill can thus also be seen as affording opportunities for individuals to engage in numeracy practices that may support the development of their numeracy beyond the identification of how much they need to pay and by when.

\section{Supports}

A citizen's individual environment is uniquely constituted - materially and socially. Their successful negotiation of the energy bill (pay the bill, make or ignore optional choices, take account of or ignore information about their projected usage) may be supported by other actors within this immediate environment. These actors - family members, friends, colleagues may explain what needs to be paid, by when and how, or discuss and explain the reasons behind the options that may be presented to them (e.g., environmental considerations). Individual citizens may be able to find support within their community outside of their immediate household or social networks through, for example literacy mediators (Baynham, 1995) in the community who can read and interpret the information and assist in the action demanded by the energy bill. This may be a service provided by a librarian in a public library - or by a multilingual person in an immigrant's ethnic community, for example. The support may consist of facility in a shared language other than the language of the energy bill, relevant numerate skills and/or knowledge about relevant debates and trends concerning energy consumption and utility services.

\section{Barriers}

Responding to the demands and opportunities presented by an energy bill may present barriers to some and require support. For a recent immigrant - even for a migrant from another part of the country (Kalman \& Solares, 2018) - some of the language, currency, payment options, overall layout and composition of an energy bill may be unfamiliar. Depending on whether the immigrant is supported within a community who could assist in the deciphering of the elements of the utility bill, by a multilingual information sheet that deconstructs the bill or by another family member who has the linguistic and other necessary resources to assist, they may find it difficult to overcome the barriers.

The OFGEM study also found that the language used in the main body of typical energy bills was clear and relatively easy to understand, but that the small print, often where explanations of the basis of calculations was explained, was far more complex, and thus difficult to access. For some, the presentation of "choices" itself may present barriers because they require new calculations or comparisons.

\section{Case Study 2: Converting the National Currency in Slovak Republic}

We can also study the relationship between the numerate environment and the development of adults' numeracy skills and practices where national policy decisions have led to changes in the demands on people's numeracy. We could for example consider the (partial) introduction of the metric 
system in countries such as the UK and Canada, in the 1970s, or those countries where the unit of currency has been changed by a factor of 100 (e.g., France in 1960), or 10,000 (Romania in 2005).

A simpler, less numerical change was undertaken by state and society in Swedish society in 1967 - from driving on the left-hand side of the road to the right-hand side. Yet spatial awareness was certainly important in that change and plays a key role in a broad sense of numeracy (cf. Kane, 2018).

In these examples from recent history, we see that the ecological levels of state and society can be very important. When a whole country adopts such a goal, it requires pervasive and long-lasting involvement of national and local institutions, as well as the participation of individuals. This has happened impressively in conversions to the euro, over a period of more than 20 years, in 19 European countries (to date).

The euro conversion process in Slovakia (2008-11) was described by Kubascikova et al. (2019). We analyse it here as a numerate environment that faced every citizen every day in Slovakia. However, it was experienced in somewhat different ways by individuals, depending on their circumstances and the resources they could deploy.
Thus, adults learned to make currency conversions in varying situations, and to develop / extend the required numeracy practices, including:

- calculation (e.g., using conversion rates);

- estimation (including judging an appropriate level of precision);

- comparison of values (e.g., judging if apparent differences are worth bothering about, given one's circumstances);

- deciding which strategies might be appropriate, for dealing with the conversion demands relevant to the adult, their family, workplace and social groups, and their practices requiring the handling of money; and

- developing these strategies and practices in context (Austria's conversion in 2002, at approx. 13.76 Austrian Schillings to one euro, raises different numeracy problems for citizens than the Slovak rate of 30.126 SKK to one - see Kubascikova et al., 2019).

The researchers nonetheless found evidence of the same types of adaptation strategies in Slovakia as found by Hofmann et al (2007) in Austria during the euro conversion from 2002. These included: (1) direct conversion; (2) marker value; (3) anchor; and (4) intuition strategies; see Table 1.

\section{Table 1: Adaptation Strategies used during Euro Conversion in Austria (ca. 2002)}

\begin{tabular}{|l|l|}
\hline \multicolumn{1}{|c|}{ Strategy } & \multicolumn{1}{c|}{ Description } \\
\hline Conversion Strategy & $\begin{array}{l}\text { Converting (by numerical calculation) each euro price into the old currency - exactly, or by rule of } \\
\text { thumb. A range of conversion tactics used by French respondents were identified by Lemaire and } \\
\text { Lecacheur (2001). }\end{array}$ \\
\hline Marker Value Strategy & Specific values are learned: for example how much $5 €, 10 €, 20 €$ is worth in the familiar currency. \\
\hline Anchor Strategy & $\begin{array}{l}\text { Learning (remembering) prices, mostly the regularly bought products. The remembered prices are } \\
\text { used as an anchor, a basis for evaluating other prices. }\end{array}$ \\
\hline Intuition Strategy & $\begin{array}{l}\text { No conversion or comparison of the euro to the old currency. People rely on their developing "price } \\
\text { intuition", buying what they need. }\end{array}$ \\
\hline
\end{tabular}

Source: Based on Hofmann et al. (2007, p. 373). 


\section{Opportunities and Demands}

We can analyse Slovakia in transition between currencies as a numerate environment. The situation provided opportunities to learn: how to convert prices from the new to the old currency, and vice versa. These might also be described as demands to engage in consumer practices in new ways. Thus, the relationship here between opportunities and demands is complex. The consequent need to engage in particular numerate practices in their everyday life made new demands on people's numeracy skills - and also provided opportunities for learning to take place. To understand the take up of those opportunities we look at the available supports in that particular numerate environment.

\section{Supports}

Of course, many Slovaks had had previous individual opportunities to use the euro, elsewhere in countries already using the euro. Once Slovakia joined the euro, national and European agencies provided substantial resources for supports especially for citizens with limited access to information or unusual needs. Here we analyse the supports offered at national / European (macro) level, mid-level meso and individual / family (micro) level.

At the national level, pedagogic materials were aimed at upper secondary students and others, relating to basic notions about the euro and "financial literacy." Tools such as pre-programmed calculators were provided to support adults wishing to produce exact conversions at any stage. In addition, "revision" of "times tables" was offered to adults.

For adults using the marker value strategy, supports included conversion tables widely distributed nationally, giving equivalent numbers of euros and crowns. For those developing an anchor strategy (as one of several), a "Bundle of Shopping" poster, showed what items could be purchased for 10 euros, 20 euros, and other amounts, was displayed nationally.

At the mid-level, there were local programmes to help specific groups with limited access to information, including: the elderly; the visually / hearing impaired; the economically vulnerable, e.g. the Roma, using drama and performing arts.

There were also interventions at the mid-level, which aimed to generate individual / family supports. Special sessions were organised by a Slovak commercial bank (VUB), using hip hop music and rap, to convey basic information about the euro to school children. The children were encouraged to write their own euro problems, for example how much things cost in euros and vice versa. The intention was to get children interested in the hope that they both would learn something about the euro, and pass it on to their families, friends and neighbours (Kubascikova-Mullen, 2013, p. 100).

\section{Barriers}

We may also consider examples of barriers, factors which threatened to constrain the individuals' ability to engage in the necessary practices to act effectively with their new currency. For example, some Slovaks feared price inflation due to the introduction of the euro, for several reasons, including experiences elsewhere in Europe. This widespread perception at the individual level led to societal level supports. For example, before the transition, businesses were encouraged to sign a voluntary "Ethical Code" concerning fair rules for conversion of prices. During the transition period, prices were closely monitored by official bodies and changes in price levels published. This helped to reassure citizens. Thus, an added aim 
of the supports was to produce positive attitudes towards the currency transition. It illustrates the importance of maintaining positive attitudes towards such a change, thus underlining an important point about numeracy (and other practices): effective engagement in practices involves affective, as well as cognitive, aspects (Evans, 2000).

Overall, this national effort provided an example of collective learning, supported by the state, of new numerate practices, with self-reinforcing effects.

\section{Discussion}

In this paper we have been seeking insights into how adults in the community experience and negotiate numeracy related demands in their everyday life. We have considered a number of illustrations, and two case studies in more detail above. This has shown the value of considering demands for engagement in numeracy practices, along with opportunities, supports and barriers, together as affordances. Our analysis also shows the importance of considering all these aspects at different levels of the numerate environment, which we have called here individual, mid-level, and national levels.

The concept of the numerate environment also helps us to see how individuals may perceive opportunities to develop new numeracy practices to negotiate the demands of their environment. Material and social supports may be afforded by the individual's immediate environment (skilled and knowledgeable family members or friends), mid-level environment (public libraries, community centres or workplace colleagues) or at the national level (state-produced factsheets and websites, consumer protection laws). Equally, however, individuals can experience barriers, not only to responding to the demand but also to taking up opportunities and supports for development - again in the different levels of the environment. These barriers may be material (e.g., lack of technological resources to access further information or to do calculations) or social (e.g., absence of a literacy mediator to help read the text outlining the demand).

Grotlüschen et al (2016) suggest that those with low numeracy and literacy proficiencies also tend to be less active in their community. We might thus speculate that when individuals experience significant barriers within their immediate or mid-level environment, they may struggle to access any support available at the national level, even if such were to exist. For example, someone who is struggling to negotiate the new method of payment of a bill and who is not connected to a social network or support services may require some "outreach" from those making the demand or within the community who is able to act as a numeracy mediator, similar to the role played by literacy mediators in communities or others participating in community organisations, mediating the numeracy practice within the individual's zone of proximal development (Vygotsky, 1978).

Researchers including Murray (2009) have argued in the context of literacy, that if the demands on many adults' skills are low, these skills may decline or fail to develop, leaving a large subclass excluded from the literate environment and relying on others for interpretation and access to information. If engaging in practices develops skills proficiencies and prevents skills loss (OECD, 2013, p. 24), then such adults risk losing the skills that they do have, by not using them. This vicious circle of underuse and consequent loss of skills should be a major concern for policy makers. 


\section{Conclusions and Recommendations}

Analysis using the numerate environment has suggested that insights into adults' competence in negotiating their everyday numeracy demands can be gained through an ecological perspective. Where individuals are socially connected to skilled and resourceful communities, they may be much more able to negotiate the numeracy demands than individuals who are socially isolated and/or living in resourcepoor communities (e.g., Grotlüschen et al., 2019). Understanding numeracy practices and development as a collective activity removes the "deficit" label on individuals and creates a demand for policy makers to consider the importance of collective numeracy and examine what opportunities and supports are afforded by the individuals' social environment.

The numerate environment is a concept that governments can employ in order to understand numeracy demands on the adult population, identify opportunities for numeracy learning that those demands present, and design social and material supports for flexible, contingent systems of learning. It reinforces the idea that poor numeracy is a social rather than an individual responsibility, suggesting the need for more campaigns and public information around numeracy, as well as careful consideration of the use of numeracy in public communications. It also suggests that policies aimed at developing a more numerate adult population are likely to succeed if they are developed in tandem with social policies aimed at reducing social isolation and other factors that may limit individuals' capacity to access supports.

The framework described in this paper also has implications for adult numeracy education practice. Shifting the gaze from the numerate individual to their numerate environment suggests that learning should start from an understanding of each learners' numerate environment: the demands it places upon them, as well as the opportunities that it offers. Their learning within the classroom can then be linked to the contexts in which they encounter numeracy demands and opportunities. This also allows the teacher to support the learner in recognising and using the supports that are available within and outside the classroom, and to "hear" learners' accounts of barriers they encounter. It also has implications for taking account of the literacy demands involved in any numerate practice, as illustrated in Case Study 1 (see also Tout \& Gal, 2015).

The shift in focus, from numeracy as an individual competence to the environment in which that competence is used, allows for the formulation of policy that addresses adult numeracy as a social, rather than an individual responsibility. For such policies to be successful there is also a need for a change in policy focus, from supply to demand, from formal systems of skills acquisition to support for informal learning, and the nurturing of engagement in numeracy practices (Reder, 2009). 


\section{References}

Anderson, C. \& Sally, D. (2013) The numbers game: Why everything you know about football is wrong. Viking.

Australian Competition and Consumer Commission (n.d.) False or misleading claims. https://www.accc.gov.au/ consumers/advertising-promotions/false-or-misleadingclaims\#examples-of-false-or-misleading-claims

Baker, D. (1998). Numeracy as social practice. Literacy and Numeracy Studies. 8(1), 37-50.

Barton, D., \& Hamilton, M. (1998). Local literacies: reading and writing in one community. Routledge.

Baynham, M. (1995). Literacy practices: Investigating literacy in social contexts. Longman.

Blastland, M., \& Dilnot, A. (2008). The tiger that isn't: Seeing through a world of numbers. Profile Books.

Bronfenbrenner, U. (1981). The ecology of human development: Experiments by nature and design. Harvard University Press.

Coben, D. (1992). What do we need to know? Issues in numeracy research. Adults Learning (England), 4(1), 15-16.

Easton, P. (2014). Sustaining literacy in Africa: Developing a literate environment. UNESCO.

EU High Level Group of Experts on Literacy (2012). Final report: September 2012. http://ec.europa.eu/education/ policy/school/doc/literacy-report_en.pdf

Europe Economics (2011) Meeting standards of conduct: Report by Europe Economics and the National Research and Development Centre for Adult Literacy and Numeracy, Institute of Education, University of London, for OFGEM (unpublished report - available on request)

Evans, J. (2000). Adults' mathematical thinking and emotions: A study of numerate practices. Routledge / Falmer.

Evans, J., Ruane. S., \& Southall, H. (Eds.) (2019). Data in society: Challenging statistics in an age of globalisation. Policy Press.
Evans, J., Yasukawa, K., Mallows, D., \& Creese, B. (2017). Numeracy skills and the numerate environment: Affordances and demands. Adults Learning Mathematics: An International Journal, 12(1), 17-26. http://www.alm-online.net/wp-content/uploads/2017/10/ almij_121_october2017.pdf

Gibson, J. J. (1986). The ecological approach to visual perception. Taylor and Francis.

Greeno, J. G. (1991). Number sense as situated knowing in a conceptual domain. Journal for Research in Mathematics Education, 22(3), 170-218. https://www. jstor.org/stable/749074

Grotlüschen, A., Mallows, D., Reder, S., \& Sabatini, J. (2016). Adults with low proficiency in literacy or numeracy. OECD education working papers No. 131. http://www.oecd.org/officialdocuments/ publicdisplaydocumentpdf/?cote $=$ EDU/ $\mathrm{WKP}(2016) 5 \&$ docLanguage $=\mathrm{En}$

Grotlüschen, A., Buddeberg, K., Redmer, A., Ansen, H., \& Dannath, J. (2019). Vulnerable subgroups and numeracy practices: How poverty, debt, and unemployment relate to everyday numeracy practices. Adult Education Quarterly, 69(4), 251-270. https://doi. org/10.1177/0741713619841132

Harding, C., Romanou, E., Williams, J., \& Peters, M. (2012). The 2011 Skills for Life Survey: A survey of literacy, numeracy and ICT levels in England: Report for BIS. BIS Research Paper.

Hofmann, E., Kirchler, E., \& Kamleitner, B. (2007). Consumer adaptation strategies: From Austrian shilling to the euro. Journal of Consumer Policy, 30(4), 367381. https://doi.org/10.1007/s10603-007-9042-5

Jackson, K., Rogers, A. \& Yasukawa, K. (2018). Expanding and deepening the terrain: Numeracy as social practice. In K. Yasukawa, A. Rogers, K. Jackson, \& B. Street (Eds.), Numeracy as social practice: Global and local perspectives (pp.243-254). Routledge. 
Kalman, J., \& Solares, D. (2018). 'Tear it out and rip it up or you might get charged again': Paying debts at the company store in a farm workers' camp in Mexico. In K. Yasukawa, A. Rogers, K. Jackson, \& B. V. Street (Eds.), Numeracy as social practice: Global and local perspectives (pp. 59-75). Routledge.

Kane, P. (2018). Estimation by kiwifruit orchard managers and urban refuse/ recycling operators within their situated horticultural or civic workplace practices: case studies from New Zealand. In K. Yasukawa, A. Rogers, K. Jackson, \& B. V. Street (Eds.), Numeracy as social practice: Global and local perspectives (pp. 21-39). Routledge.

Kubascikova, J., Evans, J., \& Khan, H. (2019).

Development of intuition in a new currency, the Euro: The Slovak experience. Literacy and Numeracy Studies, $26,1$.

Kubascikova-Mullen, J. (2013). Adult numeracy and the conversion to the Euro in Slovak Republic. PhD thesis, Middlesex University London.

Lave, J. (1998). Cognition in practice: Mind, mathematics and culture in everyday life. Cambridge University Press.

Lemaire, P., \& Lecacheur, M. (2001). Older and younger adults' strategy use and execution in currency conversion tasks: Insights from French Franc to Euro and Euro to French Franc conversions. Journal of Experimental Psychology: Applied, 7(3), 195-206.

Lind, A. (2008). Literacy for all: Making a difference (Vol. 7). UNESCO

Lupton, D. (2016). The diverse domains of quantified selves: self-tracking modes and dataveillance. Economy and Society, 45(1), 101-122.

Mallows, D. \& Litster, J. (2016). Literacy as supply and demand. Zeitschrift für Weiterbildungsforschung, 39, 171-182. https://doi.org/10.1007/s40955-016-0061-1

Murray, T. S. (2009). Longitudinal research related to the acquisition and maintenance of literacy. In S. Reder \& J. Bynner (Eds.). Tracking adult literacy and numeracy: Findings from longitudinal research on skills (pp. 85104). Routledge.
Nayak, A., \& Beckett, A. (2008). Infantilized adults or confident consumers? Enterprise discourse in the UK retail banking industry. Organization, 15(3), 407425. https://doi.org/10.1177/1350508408088537

Nunes, T., Schliemann, A., \& Carraher, D. (1993). Street mathematics and school mathematics. Cambridge University Press.

OECD (2013). Skilled for Life? Key findings from the survey of adult skills. Accessed 31 March 2019 from http://www. oecd.org/skills/piaac/SkillsOutlook_2013_ebook.pdf

Paulos, J. A. (1996). A mathematician reads the newspaper: Making sense of the numbers in the headlines. Penguin Science.

Reder, S. (2009). Scaling up and moving in: Connecting social practices views to policies and programs in adult education. Literacy and Numeracy Studies, 16(2) / 17(1), 35-50. https://doi.org/10.5130/lns.v0i0.1276

Ridgway, J, Nicholson, J., Sutherland, S., \& Hedger, S. (2019). Critical statistical literacy and interactive data visualisations. In J. Evans, S. Ruane, S., \& H. Southall (Eds.), Data in society: Challenging statistics in an age of globalisation (pp.349-358). Policy Press.

Rosling, H., with Rosling, O., \& Rosling Rönnlund, A. (2018), Factfulness: Ten reasons we're wrong about the world--and why things are better than you think. Hodder \& Stoughton.

Saxe, G. B. (1994). Studying cognitive development in sociocultural context: The development of a practicebased approach. Mind, Culture, and Activity, 1(3), 135-157.

Scribner, S. (1986). Thinking in action: Some characteristics of practical thought. In R. J. Sternberg, \& R. K. Wagner (Eds.) Practical intelligence: Nature and origins of competence in the everyday world (pp. 13-30). Cambridge University Press.

Sippitt, A. (2019). Full fact. In J. Evans, S. Ruane, S., \& H. Southall (Eds.), Data in society: Challenging statistics in an age of globalisation (pp.359-364). Policy Press.

Smeets, I. (2018). What do people like about mathematics? Adults Learning Mathematics: An International Journal, 13(1), 58-64. 
Smith, B., Sharma, P., \& Hooper, P. (2006), Decision making in online fantasy sports communities. Interactive Technology and Smart Education, 3(4), 347-360. https:// doi.org/10.1108/17415650680000072.

Street, B. V. (1985). Literacy in theory and practice. Cambridge University Press.

Street, B V., Baker, D., \& Tomlin, A. (2005). Navigating numeracies: Home/School numeracy practices. Springer.

Tomazin, F. (2018, April 22). Hundreds of 'students' complain about debts they did not know they had. Sydney Morning Herald. https:/www.smh.com.au/politics/ federal/hundreds-of-students-complain-about-debts-theydid-not-know-they-had-20180422-p4zb06.html

Tout, D., \& Gal, I. (2015). Perspectives on numeracy: Reflections from international assessments. ZDM Mathematics Education, 47, 691-706. https://doi. org/10.1007/s11858-015-0672-9.

UNESCO Institute for Education (1997). Literacy, Education and Social Development. UIE.
Van Lier, L. (2000). From input to affordance: Socialinteractive learning from an ecological perspective. In J.P. Lantolf, (Ed.) Sociocultural theory and second language learning. Oxford University Press. 245-259.

Vygotsky, L. S. (1978). Mind in society: The development of higher psychological processes. Harvard University Press.

Worthen, H. (2014). What did you learn at work today? Ten forbidden lessons of labour education. Hardball Press.

Yasukawa, K. \& Evans, J. (2019). Adults' numeracy practices in fluid and unstable contexts - An agenda for education, policy and research? Zeitschrift für Weiterbildungsforschung, 42, 343-356. https://doi. org/10.1007/s40955-019-00145-z

Yasukawa, K., Jackson, K., Kane, P. \& Coben, D. (2018). Mapping the terrain of social practice perspectives of numeracy. In K. Yasukawa, A. Rogers, K. Jackson, \& B. Street (Eds.), Numeracy as social practice: Global and local perspectives (pp.3-17). Routledge.

Yasukawa, K., Rogers, A., Jackson, K., \& Street B. (Eds.) (2018), Numeracy as social practice: Global and local perspectives. Routledge.

\section{Endnotes}

1 At the national level in the UK, Ridgway et al.'s Constituency Explorer (http://www.constituencyexplorer.org.uk/) portrays socio-economic and other differences among 600+ UK Parliamentary constituencies (Ridgway et al, 2019).

2 Nevertheless, we are sceptical of many claims made for "Big Data", by proponents. For example, much of it is decidedly not available to citizens at large - but is often harvested / appropriated by private concerns. There are tricky ownership / ethical issues; see Evans, Ruane \& Southall (2019, especially Sec. 1).

3 Van Lier drew on a more elaborate version of Bronfenbrenner's (1981) ecological framework which is a nested ecological system represented by four layers of concentric circles.

4 In order to calculate the percentage of adults in England able to carry out these tasks, data was used from the 2011 Skills for Life Survey (Harding et al, 2012). The Skills for Life Survey provides a national profile of adult literacy, numeracy and ICT skills in England. 